\title{
The politics of publishing in anthropology: introductory remarks
}

Ian Harper (University of Edinburgh) and Rebecca Marsland (SOAS, University of London)

Publishing ethnographic material is at the heart of the anthropological enterprise, and forms the basis of establishing academic careers. Yet we rarely consider the politics of our discipline from this perspective. What might the world of anthropology look like diffracted through this lens? In this edition of Anthropology Matters we reflect on our discipline from the position of the production and circulation of the products of ethnography_our finished texts.

Most of us who are in academic posts are currently grappling with the strains of the Research Assessment Exercise (RAE) and those all-important four texts required for this. Recently, when considering whether to contribute to a special edition of Social Science and Medicine, one of us was told that the most important thing was that the journal edition should be out in time for the RAE. In another conversation over a jointly authored piece, the question arose as to who would get the credit for it. A colleague who wanted to publish in a journal produced in Nepal was told by his supervisor not to waste his time, and to start thinking about publishing in serious journals. Departments are currently having dry runs to see how they will fare in the RAE; we are being told to get those publication numbers up.

For those of us still seeking lectureships, we are reminded by unions and our professional bodies that lecturers should not be selected on the grounds of their publications. Nevertheless, we all know that having that monograph makes all the difference, and publication for the RAE has recently been included on the 'person specification' for new posts (e.g. at SOAS and Sussex). We all know the score and the pecking order; the monograph comes first, preferably published with a major American or UK academic press; then there are the major anthropological journals (with the majority based in the US) and edited volumes (as long as you are the editor). Stop writing for your friend's edited volumes, was one quip recently heard, and get publishing in a decent journal.

Times have certainly changed, since the pressure is now on to publish the first monograph straight after you have passed your doctoral viva, whilst many of those who finished their $\mathrm{PhD}$ ten years ago are only now publishing their thesis as a monograph. These longer 'brewing' times, with the possibility of return trips to the field, may or may not lead to better quality scholarship - the point is that the flexibility required to fit 
different kinds of research interests is being eroded. All of us could reproduce similar stories and conversations, as the RAE, and the associated discourses of anxiety that circulate with it, constitute a considerable aspect of the existential grounds of what makes us anthropologists. We can try to deny it, but like it or not, the tail is currently wagging the dog.

How many of you now wonder about how many times you are cited (the citation index) or consider the 'impact' rating of the journal you publish in? Do a search for an article you have written on google scholar and the number of times you have been cited elsewhere will pop up. As anthropology desperately struggles to maintain a grip on the order of things-there is an independent panel to assess RAE contributions to anthropology - we have to wonder how long, in a world increasingly dominated by audit, such control can be maintained? What of those of us who struggle with questions of interdisciplinary writing? A colleague of Ian's at the WHO asked what we thought the effect of our books might be. He answered his own question: the effect of books is very limited, but if we really want to have an effect then the secret is a short letter in a journal like the Lancet or the New England Journal of Medicine (at least for those medical anthropologists who are concerned with the value of our work for broader questions of health policy). How will this impact of anthropology be measured during the RAE? Or, we might ask, should it? Do we really know what impact anthropology has through publishing, and if not, how should we go about finding out?

This raises questions of how we value the work that we do, and the relationship of that value to its policy and political effects. What is the value of work translated into local languages - or only written in local languages - and how does the definition of 'local' languages as non-English have its effects? What is the value of para-ethnographic writing for informed but non-academic audiences? If the RAE exercise is the key institutional marker that determines the value of what we do, then serious questions need to be posed to it. The effect of these bureaucratic arrangements is not dissimilar to that which happens to the core moral values of the discipline if we think of our responsibilities only in terms of ethics by committee. As we strive to see the possible futures of our discipline, are we drawn to a scenario where success is defined as publication in a major journal that values theory over all else? In our opinion this should be resisted at all costs.

When we put out a call for papers for this special edition we had hoped that some of these issues would be addressed, but the response was low. This may be related to our usual readership and authorial base; from our positions as postgraduates or as postdoctorates just beginning to venture into publishing, we gaze up through the bureaucratic haze towards areas where decisions that affect us are made. It is difficult to make sense of the politics of it all, and we baulk at the possibility of unpacking the political and bureaucratic interactions that make it up. Nonetheless the practices that mould our publishing are being significantly affected by these issues, and in turn significantly shape our relations. We pride ourselves on our disciplinary self-reflexivity, yet it is odd that these issues have not been unpacked more. To get the ball rolling we present three papers in this journal issue which examine the experiences of those who have a long-standing relation with the practice of publishing.

In the first paper, Daniel Miller questions the premise that there is a relation between publication and the actual quality of the academic work being published. He argues that 
the premise is false, because there are other interests involved that take precedence over academic content. Crucially, the economics of publishing means that publishing houses must think first about whether there is a big enough market for your book to justify the costs of a print run. This means that your esoteric work of genius is less likely to be published than a more run-of-the-mill monograph on a topic that is central to today's issues, or a mediocre text book that will sell better. The centrality of publishing to academic tenure, however, means that the scholar is in a position of dependency that can be open to abuse by the publisher. This can manifest itself in terms of long, unexplained delays, or even - rumours have it - go as far as sexual abuse.

Miller also highlights a concern with the process of peer review, and this is shared by Ian Harper and Pratyoush Onta's paper. It seems odd that as anthropologists we have paid so little reflexive attention to the informal networks and criteria of value that make up this practice. Peer reviewers are mainly recruited through the personal networks of editors, and it is within the peer review body, not the editorial board itself, that the crucial decisions about whether your paper is worthy of publication or not are made. This can lead to the counter-intuitive situation where editors must reject works that they favour, and accept some others that they might not have approved of themselves. There has been very little (if any) systematic work done that investigates how these career-defining judgements are made. Perhaps we also need to ask this question: if peer review was systematized, would it become subsumed under the 'audit' culture that has led to the unthinking approach to ethics and 'informed consent' that is concerning many of us right now?

Harper and Onta go on to discuss the dynamics of running an academic journal. Their paper gives some answers to the question of how and why journals are set up. In this case, Onta initiated the journal Studies in Nepali History and Society in order to address the lack of publishing outlets for academics actually in Nepal. Hitherto, many had been dependent on publishers mainly outside-in India, Europe and the USA. If Nepali academics were to develop their own trajectory and foster academic excellence within their country, it was essential that they held some control over the publishing process. This applies also to academics who do not come from Nepal, but who write about the country. In order to contribute to knowledge about Nepal, it is necessary to make that knowledge available in the country through local publishers, but also to work with Nepali academics - and one way of doing this is to contribute to their journals.

Christine Barry's interview with Ronnie Frankenberg adds to what we can learn from the experience of someone who has set up their own journal. Like Miller's piece, this paper gives an insider's account that contains some useful tips for those of us who are setting out to publish our research in journals for the first time, such as 'knowing your journal' and (once again) drawing on your personal networks. In contrast to Miller's observation about book publishing, Frankenberg remarks that the proliferation of journals and the pressures of the RAE has led to a lack of quality submissions.

There are several interesting issues that arise out of these papers. The first is that access to publishing is highly dependent on personalized networks-a situation that can leave postgraduate anthropologists out in the cold. The chances of your paper being published are dictated by two or more peer reviewers, in a peer review process entangled in personal connections and agendas, and shrouded in personal opinion and perhaps some 


\section{Anthropology Matters J ournal http:/ / www.anthropologymatters.com}

mysticism. This question of assessing quality, inevitably highly subjective, is complicated by the pressures of the RAE, and those of the marketplace. Success in publishing is not so much defined by academic quality, as your ability to network and to identify 'high impact' topics to write about that will attract a large readership. What then are the implications of this for those of us with 'niche' interests, or with long-term projects whose publishing outcomes might not fit the RAE timetable?

Finally, the centre of gravity in the academic publishing world seems to lie very much in the USA. Is British anthropology dependent on this 'centre' or is it still possible to define success in our own terms? And where does this leave our colleagues as many of us work closely with anthropologists in countries where publication opportunities are narrow? What responsibility do we have to work with them to improve this situation, or at least stop it from deteriorating further? With these final thoughts, it remains to say that we hope that these articles and conversations will encourage others to write and reflect further on this important area of our work.

\section{About the authors}

Ian Harper lectures in social anthropology at the University of Edinburgh. Rebecca Marsland has an ESRC postdoctoral fellowship at the School of Oriental and African Studies, University of London. 